\title{
Evaluation of Operational and Experimental Precipitation Algorithms and Microphysical Insights during IPHEx
}

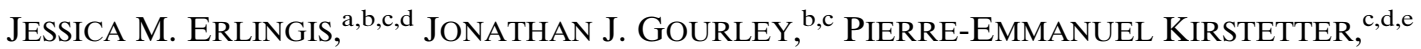 \\ Emmanouil N. AnAgnostou, ${ }^{\mathrm{f}}$ John Kalogiros, ${ }^{\mathrm{g}}$ Marios N. ANAGNOSTOU, ${ }^{\mathrm{h}}$ \\ AND WALT PETERSEN ${ }^{\mathrm{i}}$ \\ ${ }^{\text {a }}$ Cooperative Institute for Mesoscale Meteorological Studies, University of Oklahoma, Norman, Oklahoma \\ ${ }^{\mathrm{b}}$ School of Meteorology, University of Oklahoma, Norman, Oklahoma \\ ${ }^{\mathrm{c}}$ NOAA/National Severe Storms Laboratory, Norman, Oklahoma \\ ${ }^{\mathrm{d}}$ Advanced Radar Research Center, University of Oklahoma, Norman, Oklahoma \\ ${ }^{\mathrm{e}}$ Department of Civil Engineering and Environmental Science, University of Oklahoma, Norman, Oklahoma \\ ${ }^{\mathrm{f}}$ Department of Civil and Environmental Engineering, University of Connecticut, Storrs, Connecticut \\ ${ }^{\mathrm{g}}$ Institute of Environmental Research and Sustainable Development, National Observatory of Athens, Athens, Greece \\ ${ }^{\mathrm{h}}$ Department of Water Resources, School of Civil Engineering, National Technical University of Athens, Athens, Greece \\ ${ }^{\mathrm{i}}$ NASA Marshall Space Flight Center, Huntsville, Alabama
}

(Manuscript received 28 April 2017, in final form 22 October 2017)

\begin{abstract}
During May and June 2014, NOAA X-Pol (NOXP), the National Severe Storms Laboratory's dualpolarized X-band mobile radar, was deployed to the Pigeon River basin in the Great Smoky Mountains of North Carolina as part of the NASA Integrated Precipitation and Hydrology Experiment. Rain gauges and disdrometers were positioned within the basin to verify precipitation estimates from various radar and satellite precipitation algorithms. First, the performance of the Self-Consistent Optimal ParameterizationMicrophysics Estimation (SCOP-ME) algorithm for NOXP was examined using ground instrumentation as validation and was found to perform similarly to or slightly outperform other precipitation algorithms over the course of the intensive observation period (IOP). Radar data were also used to examine ridge-valley differences in radar and microphysical parameters for a case of stratiform precipitation passing over the mountains. Inferred coalescence microphysical processes were found to dominate within the upslope region, while a combination of processes were present as the system propagated over the valley. This suggests that enhanced updrafts aided by orographic lift sustain convection over the upslope regions, leading to larger median drop diameters.
\end{abstract}

\section{Introduction}

Areas of complex terrain are particularly of interest to the hydrometeorological community because of their importance to water resources, natural hazards such as flash flooding and landslides, and challenges in obtaining atmospheric and hydrologic measurements. The influence of orography on rainfall patterns, the drop size distribution (DSD), and the associated microphysical processes have received attention with the goal of improving the understanding of the structure of precipitation and its link with the hydrometeorological processes (Gori and Joss 1980; Prat and Barros 2010; Porcù et al. 2013; Wilson and Barros 2014). A specific

Corresponding author: Jessica M. Erlingis, jerlingis@ou.edu type of orographically enhanced precipitation process, in which precipitation growth occurs primarily below the freezing level through the collision-coalescence process, is particularly dangerous, as it triggers flooding events and can be underestimated by weather radars and satellite spaceborne sensors (Vitale and Ryan 2013; Grams et al. 2014). This underestimation is the consequence of DSDs consisting of relatively high concentrations of small drops (Squires 1956; Ulbrich and Atlas 2008) and median droplet size increasing toward the surface $(\mathrm{Xu}$ et al. 2008).

In addition to the vertical DSD variability effect, quantitative estimates of precipitation using operational radars in mountainous terrain suffer from ground clutter, partial beam blockage, limited measurement of the vertical structure of precipitation, and spatial variability 


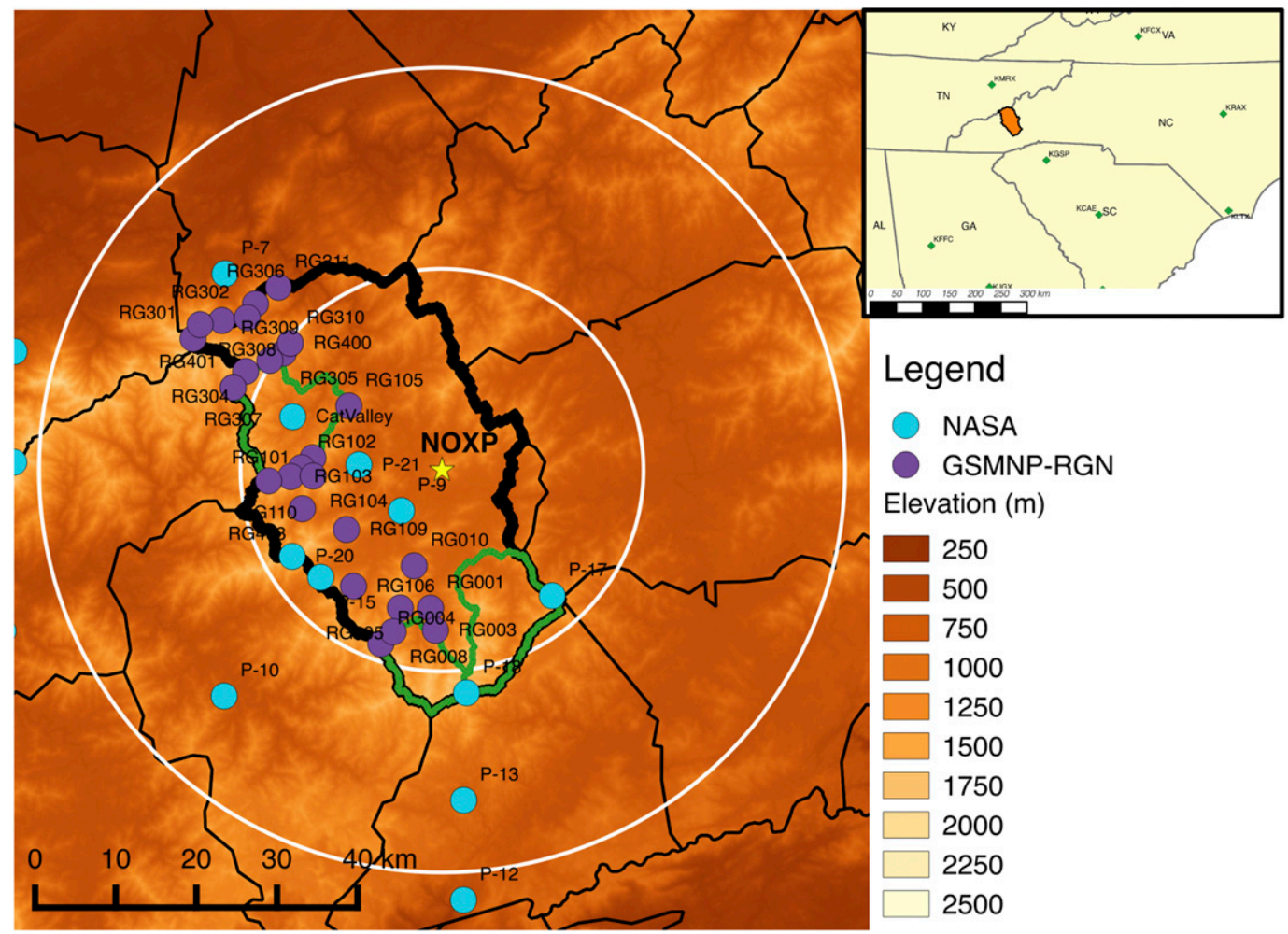

FIG. 1. Map of NOXP (yellow star) and the surrounding vicinity. Outlined in black is the PRB, and its subcatchments are outlined in green. Disdrometer sites (with collocated PARSIVEL disdrometers and NASA dualplatform rain gauges) are marked with blue circles, and GSMNP-RGN gauges are marked with purple circles. Range rings correspond to 25 and $50 \mathrm{~km}$ from the radar.

of the DSD governing $Z-R$ relationships (Klazura and Imy 1993; Westrick et al. 1999; Young et al. 1999; Maddox et al. 2002; Krajewski et al. 2006). These factors limit the measurement of the vertical structure of precipitation (especially at low levels) and the spatial variability of DSD. To mitigate these problems, highfrequency gap-filling radars may be positioned in complex terrain to supplement operational coverage (Matrosov et al. 2005; Gourley et al. 2009; Jorgensen et al. 2011; Picciotti et al. 2013).

Traditionally, radar-rainfall relationships are of the power law form $Z=a R^{b}$, but including dualpolarization information can reduce uncertainty due to the effect of DSD variability on the $Z-R$ relationship. Specifically, polarimetric radar data provide detailed information regarding the microphysical properties of precipitation such as hydrometeor phase, size, shape, and orientation (Zrnić and Ryzhkov 1999; Ryzhkov et al. 2005a). It is often possible to discern the dominant precipitation microphysical processes in precipitation by analyzing their polarimetric signatures. Specific differential phase (KDP) is independent of receiver and transmitter calibrations and is unaffected by attenuation (which is advantageous at X-band frequency), less affected by beam blockage, and unaffected by ground clutter. Specific differential phase is also useful in regions experiencing beam blockage and in detecting the radar bright band (which can cause overestimation if using a $Z-R$ relationship) (Zrnić and Ryzhkov 1999). At X-band, KDP is nearly linearly related to rainfall rate, making formulations of rainfall algorithms convenient (Ryzhkov et al. 2005a; Cifelli et al. 2011). Other radar-rainfall relationships include similar power law expressions of rainfall with reflectivity $Z$, differential reflectivity $Z_{\mathrm{DR}}$, and KDP (Bringi and Chandrasekar 2001; Ryzhkov et al. 2005b; Anagnostou et al. 2013), though a new algorithm for dual-polarization quantitative precipitation estimation (Kalogiros et al. 2013) based on microphysical retrievals is tested in this study.

The study of orographic precipitation and its related mechanisms has led to specific experiments in mountainous regimes. In particular, the meteorology and hydrology of the Great Smoky Mountains have been the focus of studies related to precipitation processes in previous years (Prat and Barros 2010; Wilson and Barros 2014, 2015; Duan et al. 2015). Wilson and Barros (2014) 
TABLE 1. Characteristics of NOXP.

\begin{tabular}{lc}
\hline \hline Latitude & $35.56419^{\circ} \mathrm{N}$ \\
Longitude & $82.91123^{\circ} \mathrm{W}$ \\
Altitude MSL $(\mathrm{m})$ & 1176 \\
Frequency $(\mathrm{MHz})$ & 9410 \\
Wavelength & $3.22 \mathrm{~cm}$ \\
Peak power at antenna port $(\mathrm{kW})$ & $162.2(81.1$ per channel) \\
Antenna type & Parabolic dish \\
Antenna gain $(\mathrm{dB} i)$ & 45.5 \\
-3-dB antenna aperture & $0.9^{\circ}$ \\
Polarization & Dual linear \\
Rotation speed $(\mathrm{rpm})$ & $0-5$ \\
Range & $111 \mathrm{~km}$ (for 1350 pulses s $\left.{ }^{-1}\right)$ \\
Pulse length & $1 \mu \mathrm{s}$ \\
\hline
\end{tabular}

relate the increase of reflectivity toward the ground in Micro Rain Radar observations with the interactions between low-level clouds and fog and precipitation, as well as model moisture convergence patterns required to produce the low-level phenomena. An intensive observation period (IOP) for the Integrated Precipitation and Hydrology Experiment (IPHEx; Barros et al. 2014), part of the NASA's ground validation (GV) campaign for the Global Precipitation Measurement (GPM; Hou et al. 2014) mission satellite launched 27 February 2014, took place from 1 May to 15 June 2014 in the Great Smoky Mountains of western North Carolina. As part of the experiment, the National Severe Storms Laboratory's (NSSL) mobile dual-polarization X-band radar, NOAA X-Pol (NOXP), was deployed to the Pigeon River basin (PRB). During that time, several events were sampled, ranging from morning fog to diurnally driven convection to landslide-inducing thunderstorms. The field experiment also leveraged a network of tipping-bucket rain gauges [Great Smoky Mountain National Park Rain Gauge Network (GSMNP-RGN)], which has been in place in the southern Appalachians since 2007 as a joint endeavor between Duke University and the University of North Carolina at Asheville. Additional ground instrumentation included a network of dual-platform rain gauges, a disdrometer network, NASA's NPOL S-band radar, and NASA's groundbased radar, D3R (Chandrasekar et al. 2010). The NASA ER-2 and the University of North Dakota (UND) Citation aircraft carried a number of passive and active sensors, and the GPM satellite also sampled events during this time. The locations of relevant ground instrumentation and NOXP are shown in Fig. 1. A description of the ground instrumentation is included in section $2 \mathrm{a}$.

The purposes of this study are 1) to evaluate the performance of several different precipitation algorithms to assess the utility of a gap-filling radar in complex terrain

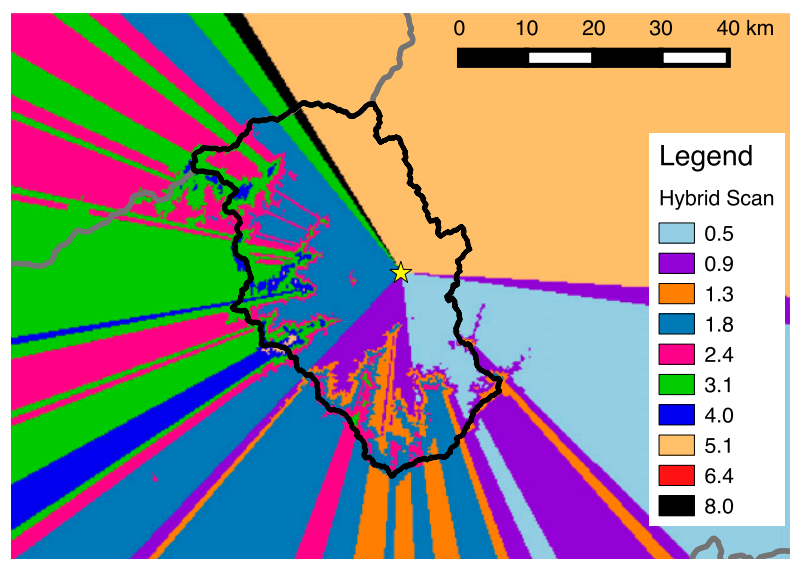

FIG. 2. Hybrid scan constructed to account for beam blockage from terrain and other obstacles near the radar site.

and 2) to examine the evidence for possible orographic enhancement near local climatological precipitation maxima. The precipitation algorithms include a variety of radar and satellite techniques. Additionally, products being evaluated have different spatial and temporal resolutions and quality control measures. The precipitation algorithms to be evaluated in this work are as follows: 1) Stage IV ( $\sim 4 \mathrm{~km}$ grid spacing/hourly), 2) multiradar multisensor (MRMS) radar-only estimates $(1 \mathrm{~km}$ grid spacing/5 min), 3) MRMS gauge-corrected (GC) estimates (1 km grid spacing/hourly), 4) NOXP dualpolarization QPE (gridded to $250 \mathrm{~m} / \sim 5 \mathrm{~min}$ for azimuth surveillance mode), and 5) the Climate Prediction Center morphing method (CMORPH; $8 \mathrm{~km} /$ hourly).

Section 2 describes relevant instrumentation deployed during IPHEx as well as the rainfall algorithms. Section 3 presents an evaluation of the performance of the precipitation algorithms over the IOP and a microphysical analysis of a rainfall event impinging on terrain on 27 May 2014. Summary and conclusions are contained in section 4 .

\section{Methodology}

\section{a. Instrumentation}

The specifications for NOXP are shown in Table 1. The NOXP site was located on a ridge below the Chambers Mountain fire station near the center of the Pigeon River basin. The scanning strategy was a series of plan position indicator (PPI) surveillance scans in a modified volume coverage pattern (VCP) 12, with the addition of a $0.1^{\circ}$ tilt. Given a pulse repetition frequency of $1350 \mathrm{~s}^{-1}$, the radar data had an unambiguous range of $111 \mathrm{~km}$. Unfortunately, the radar experienced severe blockage due to nearby trees and terrain at lower 


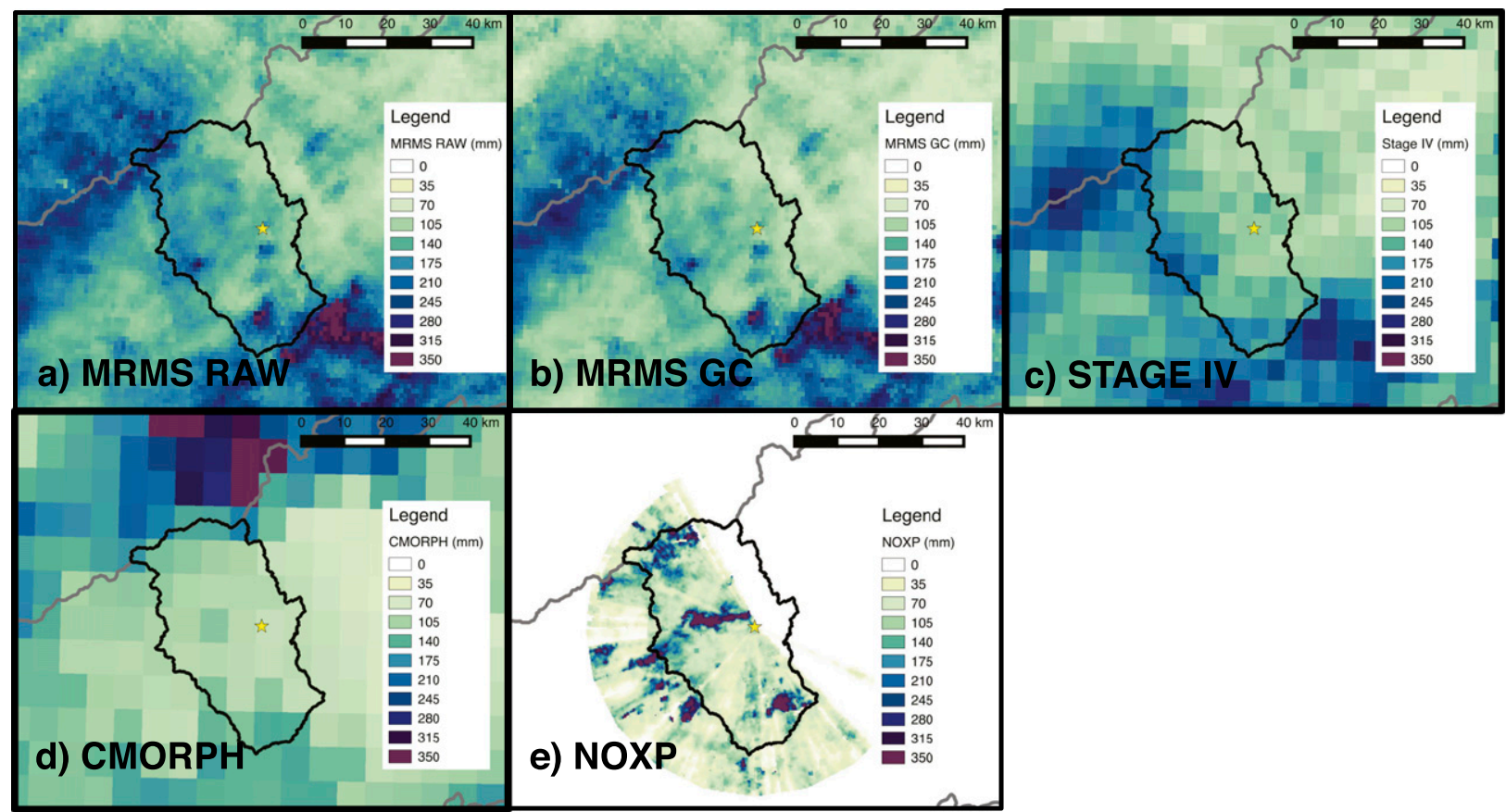

FIG. 3. 1 May-15 Jun precipitation accumulations for hours when NOXP was operating for (a) MRMS radar only, (b) MRMS gauge corrected, (c) Stage IV, (d) CMORPH, and (e) NOXP.

elevation angles from about $330^{\circ}$ to $115^{\circ}$ in azimuth. However, NOXP was positioned to sample the atmosphere above networks of ground instrumentation and three small catchments within the larger PRB previously studied by Tao and Barros (2013): the Cataloochee Creek basin $\left(128 \mathrm{~km}^{2}\right)$, the East Fork Pigeon River basin $\left(131 \mathrm{~km}^{2}\right)$, and the West Fork Pigeon River basin $\left(71 \mathrm{~km}^{2}\right)$. The radar was also capable of performing range-height indicator (RHI) scans and vertically pointing scans for differential reflectivity $Z_{\mathrm{DR}}$ calibration. RHI scans were performed primarily in coordination with aircraft and NPOL at the direction of mission scientists, but also for storms of interest to the radar operator. In total, NOXP collected nearly $182 \mathrm{~h}$ of data and over $3300 \mathrm{RHI}$ scans. Hybrid scans were produced based on the beam height above terrain (shown in Fig. 2), with a correction to account for trees near the radar site, especially to the west and southwest.

\section{b. Precipitation algorithms}

Stage IV precipitation (Lin and Mitchell 2005) is available hourly from NCEP on the Hydrologic Rainfall Analysis Project (HRAP) grid, which has 4-km grid spacing nominally. It is an hourly multisensor product including estimates from the WSR-88D operational radar network, GOES infrared satellite products, and rain gauges, and it includes manual quality control from forecasters at River Forecast Centers (RFCs).
The MRMS (Zhang et al. 2016) suite of products includes a national mosaic of instantaneous rainfall rate at $0.01^{\circ} \times 0.01^{\circ}$ grid spacing and 2-min temporal resolution. These estimates are computed from a mosaic of hybrid scan reflectivity that includes weights for how far in range the pixel is from nearby radars. An appropriate $Z-R$ relationship is chosen based on the inferred precipitation type based on both radar and environmental data at each grid point. This study incorporates both the radar-only QPE product and the product adjusted based on Hydrometeorological Automated Data System gauge corrections.

The CMORPH (Joyce et al. 2004) precipitation estimates are generated from infrared (IR) measurements from multiple geostationary satellites and from passive microwave (PMW) precipitation estimates aboard other satellite platforms, which are available at coarser temporal resolutions. The "morphing" in the moniker CMORPH refers to using the IR data to propagate the features seen in the more infrequent PMW precipitation estimates to generate global precipitation estimates in half-hourly increments at 8 -km resolution.

The Self-Consistent Optimal ParameterizationMicrophysics Estimation (SCOP-ME) radar-processing algorithm applied to the NOXP for radar observations in liquid precipitation is described in detail in Kalogiros et al. (2013), Anagnostou et al. (2013), and Kalogiros et al. (2014), based on their work with the National Observatory 
a) MRMS RAW

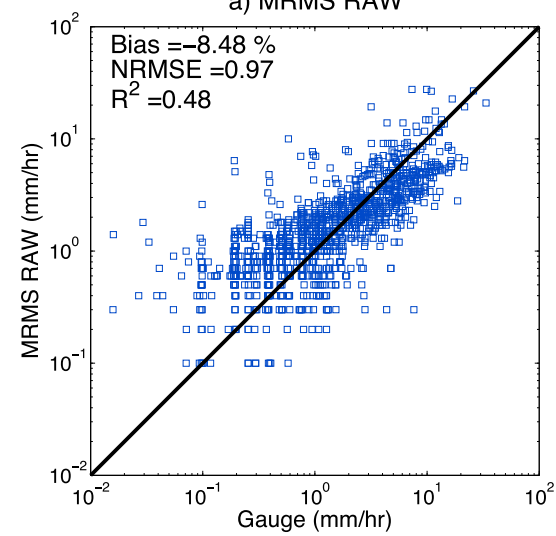

d) $\mathrm{CMORPH}$

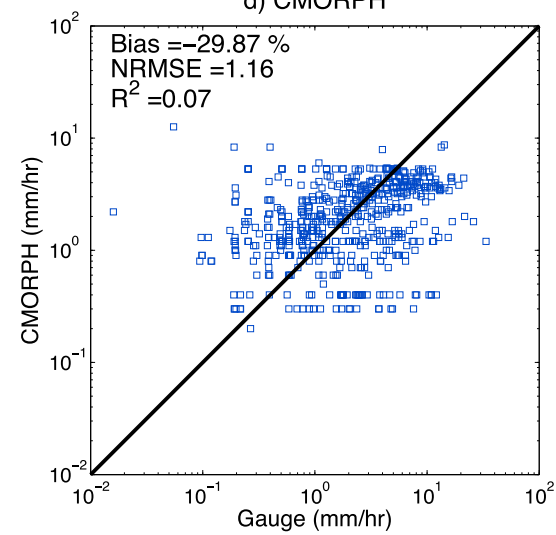

b) MRMS GC

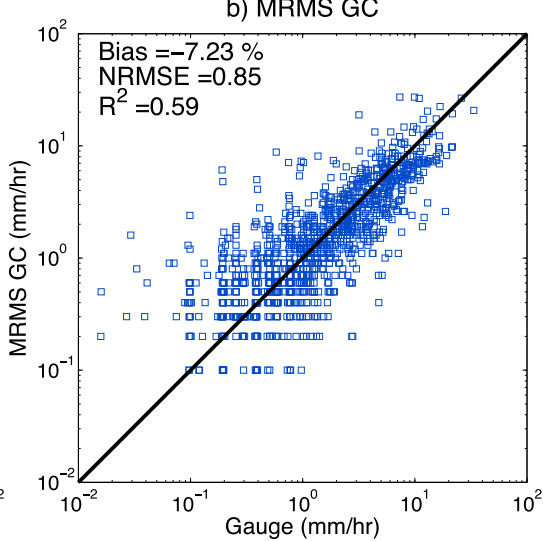

e) NOXP

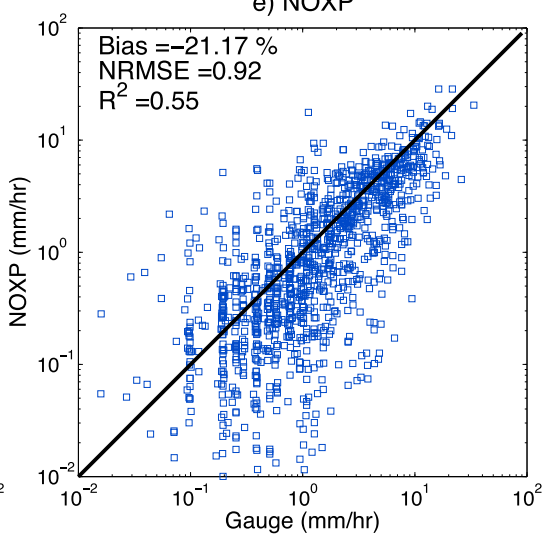

c) STAGE IV

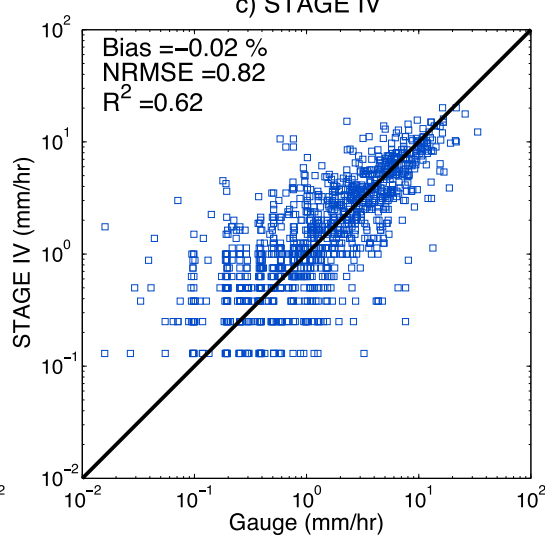

f) NOXP

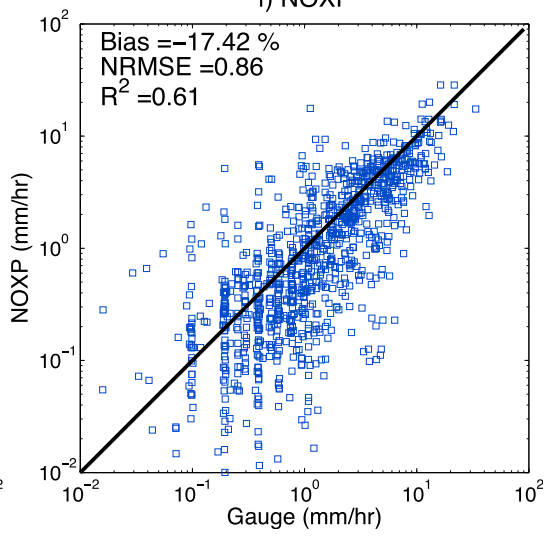

FIG. 4. Comparison with the GSMNP-RGN for (a) MRMS radar only, (b) MRMS gauge corrected, (c) Stage IV, (d) CMORPH, (e) NOXP, and (f) NOXP for gauges with less than $1500 \mathrm{~m}$ between the gauge and radar volume.

of Athens mobile dual-polarization Doppler X-band radar (XPOL). Once the radar volume has been quality controlled and then corrected for attenuation (only in the selected liquid precipitation regimes) and brightband effects as in Kalogiros et al. (2013), the precipitation rate is estimated as follows (Anagnostou et al. 2013):

$$
R=0.8106 F_{R}(\mu) N_{W} D_{0}^{4.67} f_{R_{2}}\left(D_{0}\right) .
$$

The rainfall rate is based on a normalized gamma drop size distribution (Testud el al. 2000; Illingworth and Blackman 2002):

$$
n(D)=N_{W} f(\mu)\left(\frac{D}{D_{0}}\right)^{\mu} \exp \left[-(\mu+3.67) \frac{D}{D_{0}}\right]
$$

where $n(D)\left(\mathrm{m}^{-3} \mathrm{~mm}^{-1}\right)$ is the volume density, $D_{0}(\mathrm{~mm})$ is the median volume diameter, $N_{W}\left(\mathrm{~mm}^{-1} \mathrm{~m}^{-3}\right)$ is the intercept parameter, and $\mu$ is the shape parameter of the DSD. In Eq. (1), the factor $f_{R_{2}}\left(D_{0}\right)$ accounts for an exponential relationship between terminal velocity and drop diameter. The other variables in Eq. (1) are determined from radar measurements by

$$
\begin{aligned}
F_{R}(\mu)= & 0.6 \times 10^{-3} \pi \times 3.78 \frac{6}{3.67^{4}} \frac{(3.67+\mu)^{\mu+4}}{\Gamma(\mu+4)} \\
& \times \frac{\Gamma(\mu+4.67)}{(\mu+3.67)(\mu+4.67)},
\end{aligned}
$$

where $\Gamma$ is the gamma function and $\mu$ is the shape parameter. The remaining DSD parameters, $D_{0}$ and $N_{W}$, are estimated using third-order rational polynomial regression functions to characterize the Mie scattering effects, while $\mu$ is constrained using long-term disdrometer

TABLE 2. Summary statistics for rainfall products.

\begin{tabular}{lccc}
\hline \hline \multicolumn{1}{c}{ Product } & $\begin{array}{c}\text { Normalized } \\
\text { bias }\end{array}$ & NRMSE & $R^{2}$ \\
\hline MRMS (raw) & $-8.48 \%$ & 0.97 & 0.48 \\
MRMS (GC) & $-7.23 \%$ & 0.85 & 0.59 \\
Stage IV & $-0.02 \%$ & 0.62 & 0.62 \\
CMORPH & $-29.87 \%$ & 1.16 & 0.07 \\
NOXP & $-21.17 \%$ & 0.92 & 0.55 \\
NOXP $(d z<1500 \mathrm{~m})$ & $-17.42 \%$ & 0.86 & 0.61 \\
\hline
\end{tabular}




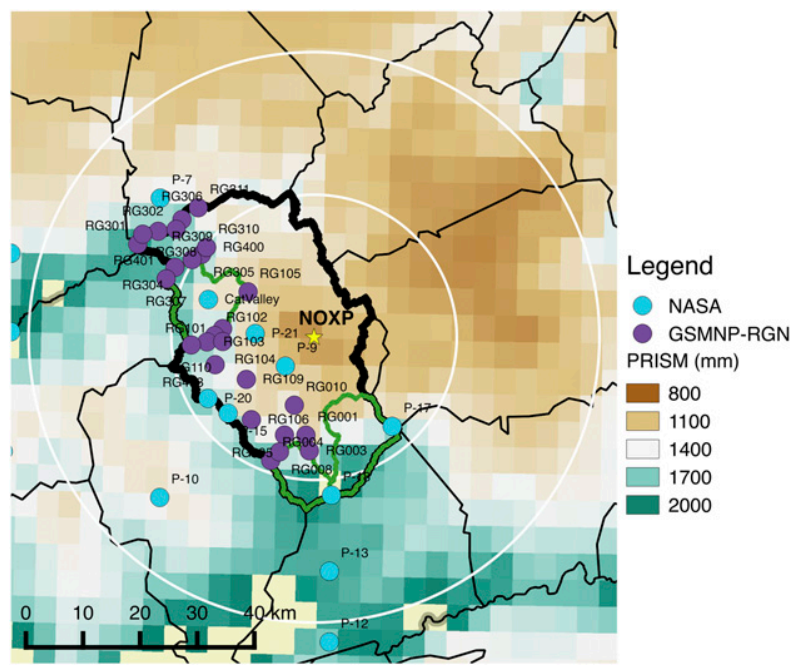

FIG. 5. PRISM annual rainfall climatology $(\mathrm{mm})$ over the IPHEx domain

data. The reader is referred to the aforementioned references for a complete description of the SCOP-ME algorithm. A $-10-\mathrm{dB}$ bias in reflectivity was found when checking the calibration of NOXP against the nearest disdrometer. After the bias was removed, this algorithm was used to process the raw NOXP data and produce precipitation estimates. The ground validation campaign data have been published online at https://fcportal.nsstc. nasa.gov/iphex/.

\section{Results}

\section{a. Performance of precipitation algorithms}

The spatial patterns of precipitation for the IOP period (1 May-15 June 2015) during the hours when NOXP was operating are shown in Fig. 3. The finer grid spacing of the MRMS products provides a more refined picture of precipitation patterns than the Stage IV product. The CMORPH satellite product shows lower precipitation totals across the basin. While the NOXP accumulations reveal some radial discontinuities due to uncorrected blockages, the measurements capture the finer details in the western part of the basin, specifically the local maximum along the ridgeline to the west of the radar.

The performance of the precipitation algorithms was evaluated using the normalized bias, normalized rootmean-square error (NRMSE), and Pearson correlation coefficient relative to both the GSMNP-RGN and the network of dual-platform NASA gauges. Gauges that were flagged for quality control issues (clogged, tipped over, etc.) were not used. Dual-platform gauges that differed by more than $10 \%$ were also discarded. The GSMNP-RGN spans a larger range of elevations than the network of NASA gauges, as the former gauges were specifically placed to study precipitation processes at high elevations. Heights for gauges used in this study in the GSMNP-RGN range from 925 to $2003 \mathrm{~m}$, while the NASA gauges are sited from 589 to $1956 \mathrm{~m}$. Additionally, Particle Size Velocity (PARSIVEL; Löffler-Mang and Joss 2000) disdrometers were collocated with dualplatform NASA gauges at some sites.

For consistency, only hours when NOXP was operating were considered for the analysis, though the other products were available outside of this time frame. Scatterplots comparing the QPE produced by each algorithm to ground observations are shown in Fig. 4 for hourly accumulations for the IPHEx IOP period (1 May-15 June). The lowest unblocked (less than $5 \%$ blockage) elevation angle for NOXP was used, and the analysis was restricted to hours with greater than 0.01-mm accumulation and an hourly average of less than 5\% melting layer contamination. Bulk statistics are shown in Table 2.
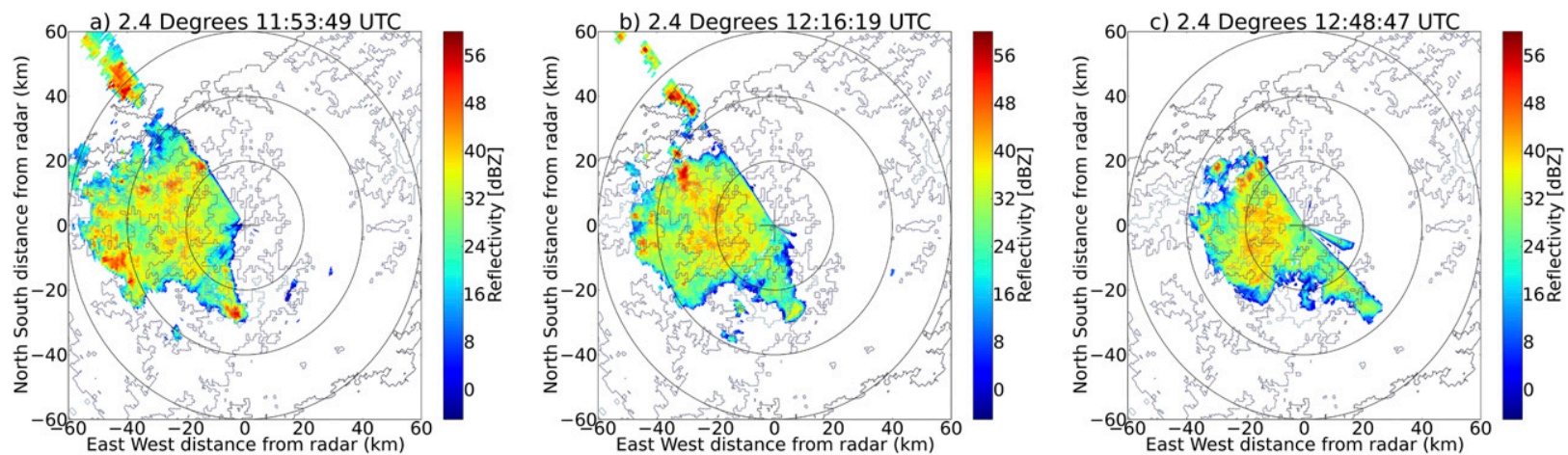

FIG. 6. Radar reflectivity for PPI scans at the $2.4^{\circ}$ elevation angle for (a) 1153 , (b) 1216 , and (c) 1248 UTC. Range rings are shown every $20 \mathrm{~km}$ from the radar. Underlying terrain is contoured every $500 \mathrm{~m}$. 

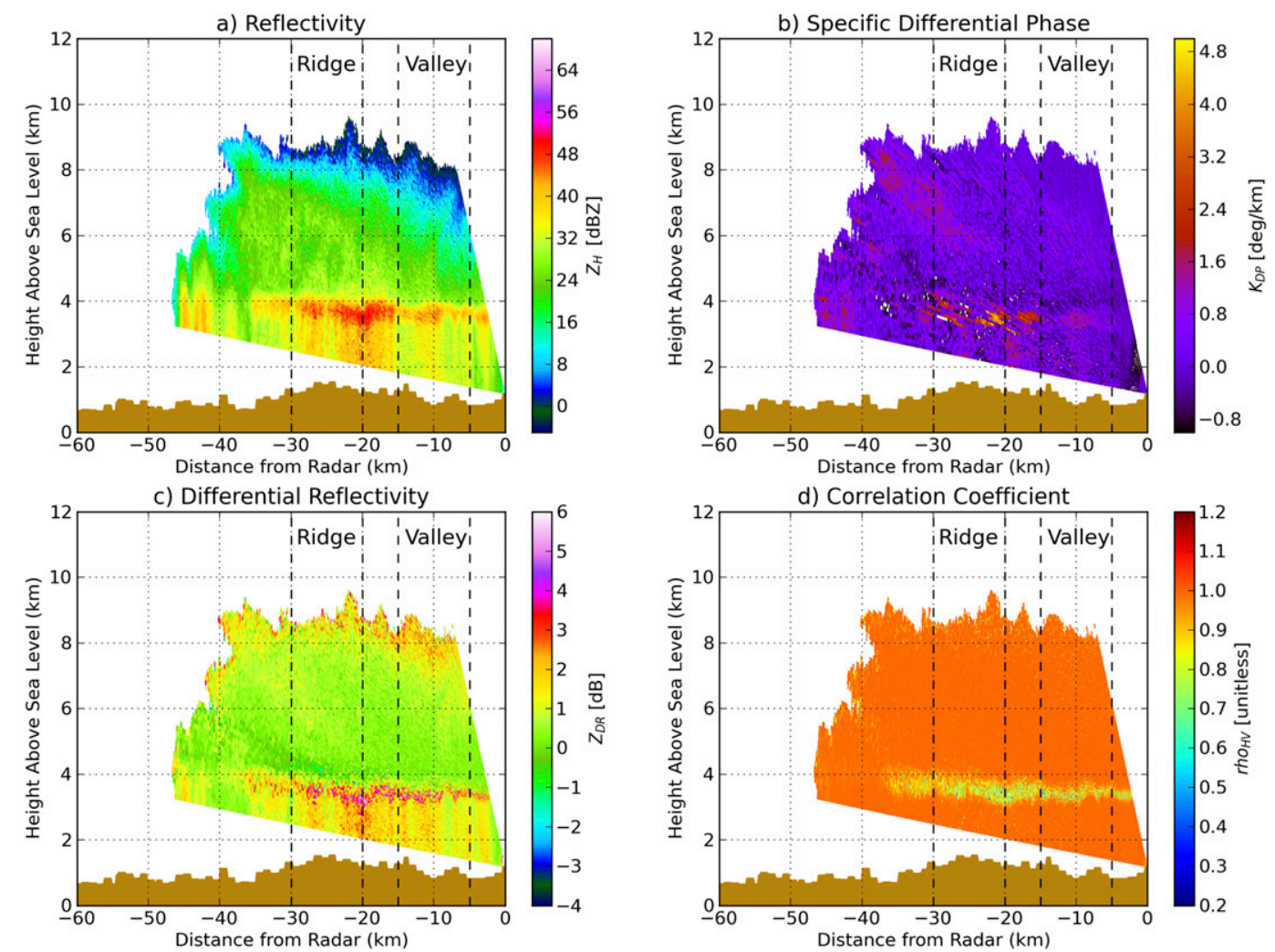

FIG. 7. RHI scan at 1221 UTC at $260^{\circ}$ in azimuth for (a) reflectivity, (b) specific differential phase, (c) differential reflectivity, and (d) correlation coefficient. The terrain height is filled along the $x$ axis.

The products derived from operational radars, STAGE IV, and MRMS are relatively unbiased, though these products are subjected to the challenges radars face in complex terrain. The satellite-based CMORPH product does not estimate higher rain rates well, but it correlates better for lower rain rate events. Additionally, satellite products that are dependent on cloud-top temperatures will not capture enhanced rain rates because of microphysical processes in the liquid phase of the cloud, including collision-coalescence processes. Though negatively biased because of its detection of small rainfall rates, the precipitation estimates from NOXP show slightly better performance than those derived from the operational WSR-88Ds before the products have been postprocessed and corrected by gauges. Precipitation from NOXP performs similarly to postprocessed radar products (MRMS GC and Stage IV), even though the NOXP estimates have not been corrected by gauges. Similar performance with the SCOP-ME algorithm has been shown at other field sites with complex terrain, such as northeast Italy (Anagnostou et al. 2017) and Athens, Greece (Anagnostou et al. 2013; Kalogiros et al. 2013). The improved low-level coverage provided by NOXP captures near-ground microphysical processes in greater detail, and an illustrative example of its utility in areas of complex terrain is presented in the following section.

\section{b. Orographic enhancement of precipitation}

The PRISM climatology of precipitation (Daly et al. 1994, 2008) over the PRB is shown in Fig. 5. The PRISM climatology is a regression from station data onto DEM cells weighted by several factors: location, elevation, proximity to the coast, and orientation of the topography, among others. Local maxima in precipitation are found along ridgelines to the west and south of the PRB, and it is posited that orographic enhancement of precipitation is a cause of these patterns. The PPI and RHI NOXP data were examined to find cases where storms were propagating upslope. Of these data, the case of widespread stratiform precipitation with embedded convection (Fig. 6) in the morning hours of 27 May 2014 was sampled by NOXP and will be presented as a case study of orographic effects on precipitation microphysics. Preceding the event, fog and low-level clouds were observed, characteristic of the Great Smoky Mountains. Surface winds were from out of the west-southwest to west, resulting in upslope flow in the western portion of the PRB. 

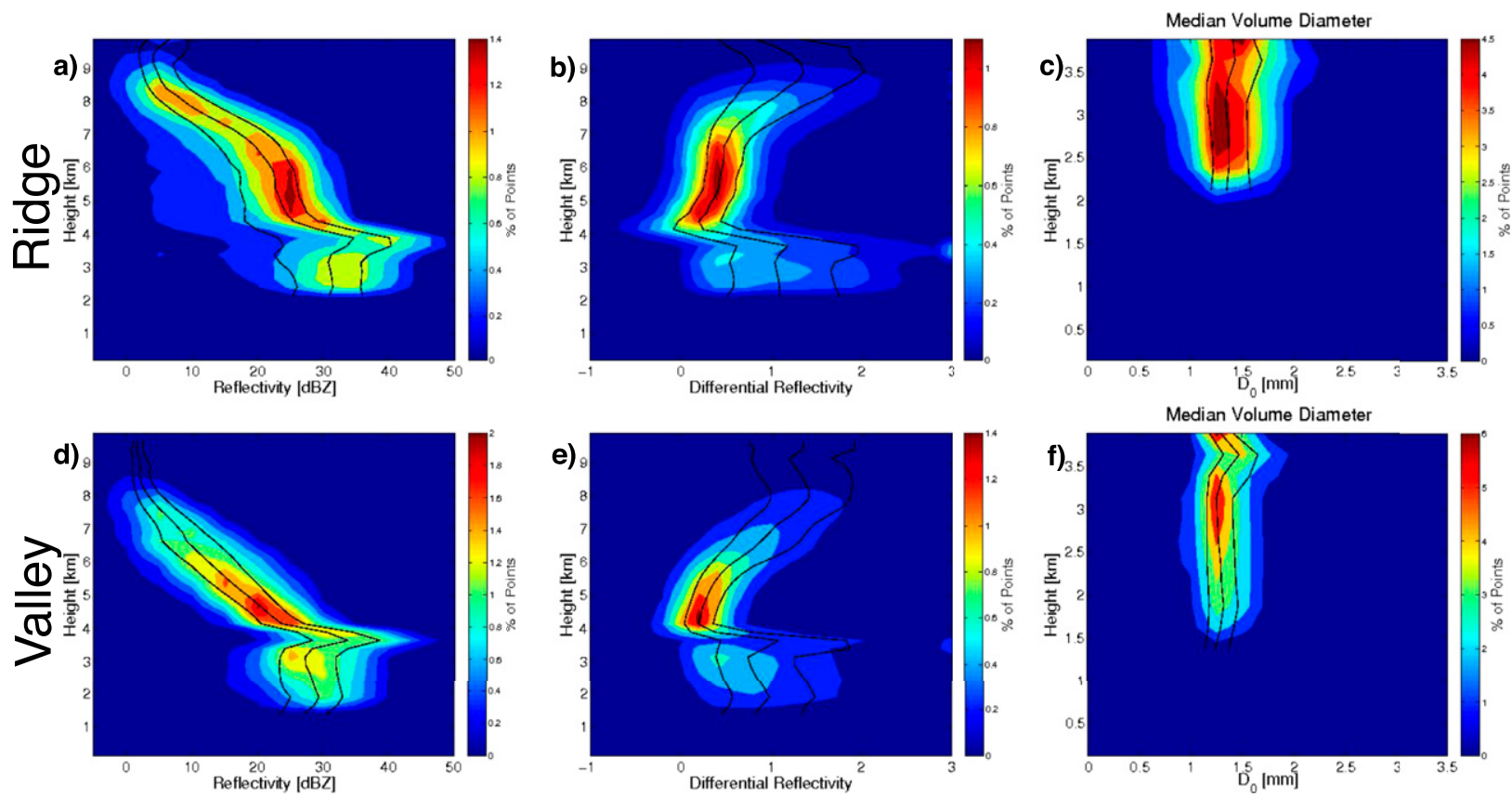

FIG. 8. CFADs from RHI scans in the 1200-1300 UTC hour over the (top) ridge and (bottom) valley for (a),(d) reflectivity; (b),(e) differential reflectivity; and (c),(f) median volume diameter. Quantile values for the 25th, 50th, and 75th percentiles are overlaid in black.

Over the course of the event, the radar operator performed sets of RHIs for areas of interest, interspersed with volume scans to accomplish the primary objective of precipitation estimation. Three sets of RHIs were performed within the 1200 UTC hour for a total of 54 scans. A representative example of the structure of precipitation in the RHIs is shown in Fig. 7. There is a well-defined bright band just below $4 \mathrm{~km}$ MSL, with the heaviest precipitation falling along the ridgeline and tapering off toward the valley. The polarimetric signatures present include the prominent melting layer (high $Z$ and $Z_{\mathrm{DR}}$; low correlation coefficient) and a signature of riming over the higher terrain. The signature of riming includes an increase of $Z$ and a decrease of $Z_{\mathrm{DR}}$ from the upper regions of the cloud toward the melting layer and a "sagging" of the bright band due to the increased terminal velocity of falling rimed particles (Kumjian et al. 2016). Below the melting layer, there is an increase of $Z$ and $Z_{\mathrm{DR}}$ toward the ground because these particles are becoming liquid, are large in size, and are efficient collectors of smaller drops as they fall.

Contoured frequency by altitude diagrams (CFADs; Yuter and Houze 1995) of reflectivity and differential reflectivity are shown in Figs. 8a, 8b, 8d, and 8e for the RHI scans at ridge and valley locations. The ridgeline is defined as $20-30 \mathrm{~km}$ in range from $225^{\circ}$ to $315^{\circ}$ in azimuth. The valley locations are defined as $5-15 \mathrm{~km}$ in range for the same azimuthal sector. RHIs were used in lieu of PPIs at this stage because of the limited vertical extent of the VCP over the valley locations. Of the 54 RHI scans within this time frame, 20 occurred within this sector. The 25th-, 50th-, and 75th-percentile values are shown at each height bin. The CFADs reveal a wider distribution of $Z$ and $Z_{\mathrm{DR}}$ over the ridgeline and narrower distributions over the valley. The magnitudes of $Z$ and $Z_{\mathrm{DR}}$ values over the ridge are larger over the vertical profile than those over the valley. The slope in reflectivity with height above the melting layer is steeper over the valley than over the ridge. This characteristic has been observed previously by Wilson and Barros (2014) using Micro Rain Radars at the seasonal time scale. The vertical profile over the ridge reveals the presence of two different slopes in reflectivity above the bright band, including a segment centered on $25 \mathrm{dBZ}$ from 4 to $7 \mathrm{~km} \mathrm{MSL}$. This is due to a higher concentration of supercooled liquid water droplets and/or the riming of ice particles. The nearly vertical slope of $Z_{\mathrm{DR}}$ values greater than zero in the same region would also suggest that this is likely. Over the terrain, updrafts may be enhanced and sustained, promoting the existence of these hydrometeors. Above $7 \mathrm{~km}$, the profiles over the ridge and valley are quite similar.

CFADs were also produced for the median volume diameter $D_{0}$ of the DSDs and are shown in Figs. $8 \mathrm{c}$ and 8f. As with the profiles of $Z$ and $Z_{\mathrm{DR}}$, the profiles of $D_{0}$ over the valley have a narrower distribution than those 

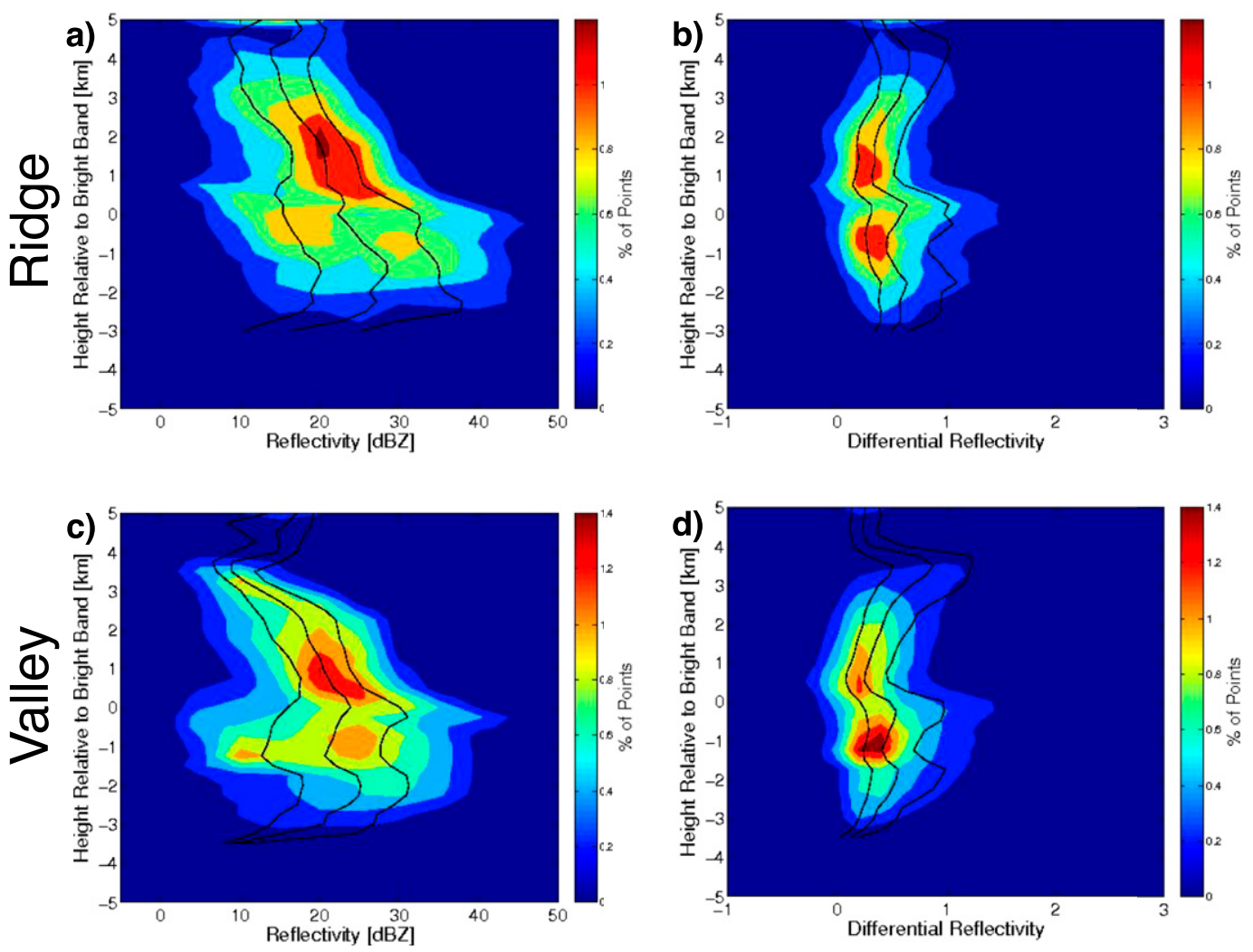

FIG. 9. CFADs from RHI scans for selected cases with a stratiform component over the (top) ridge and (bottom) valley for (a),(c) reflectivity and (b),(d) differential reflectivity. Heights are relative to the brightband position. Quantile values for the $25 \mathrm{th}, 50 \mathrm{th}$, and 75 th percentiles are overlaid in black.

over the ridge. The larger drops over the ridgeline suggest the dominance of coalescence processes and convection over the mountains. The concentration of smaller drops over the ridgeline (spectra corresponding to the left-hand side of the distribution of $D_{0}$ ) were also observed over the mountains during the Hydrological Cycle in Mediterranean Experiment (HyMEX) field campaign in France and were attributed to the presence of updrafts resulting in longer falling times for small drops (Zwiebel et al. 2016). This is also a possible explanation for this observation, as well as some contribution from breakup as the larger drops fall.

Although the primary goal of NOXP's scanning strategy during the IOP was to generate basinwide QPE over the PRB, and RHIs were primarily performed in support of research aircraft operations, there was a small subset of RHIs of opportunity. Four brief, additional time periods with stratiform signatures present (19251955 UTC 25 May, 0334-0402 UTC and 2323-2356 UTC 5 June, and 2302-2314 UTC 12 June) were included with the RHI scans from 27 May to produce CFADs (relative to the position of the bright band) from a total of 131 RHIs in the sector of interest (Fig. 9). These data reflect the same general patterns as those in the 27 May case, with steeper slopes and higher values in reflectivity over the ridge above the bright band, indicative of larger supercooled liquid water content in this space. Below the bright band over the ridge, slopes of $Z$ and $Z_{\mathrm{DR}}$ are more negative, which is indicative of coalescence processes. Distributions of reflectivity and $Z_{\mathrm{DR}}$ values from the bright band to the surface also have a larger right tail over the ridge, indicating the presence of larger drops and/or melting aggregates at this location. Because the 27 May case had the most spatial coverage of the stratifom region, only those RHI scans will be considered in the subsequent analysis.

To discern the microphysical processes governing the precipitation in the 27 May case, the framework described by Kumjian and Ryzhkov (2012) (henceforth KR) and used in Kumjian and Prat (2014) was employed. Within this parameter space, the differences in reflectivity and differential reflectivity between bins just below the bright band and bins at the lowest gate (representing the surface; median fall distances of 870 and $1370 \mathrm{~m}$ for the ridge and valley, respectively) are used to determine the dominant microphysical regime of the 
a) Aggregate RHI Valley 27 May $1200-1300$ UTC

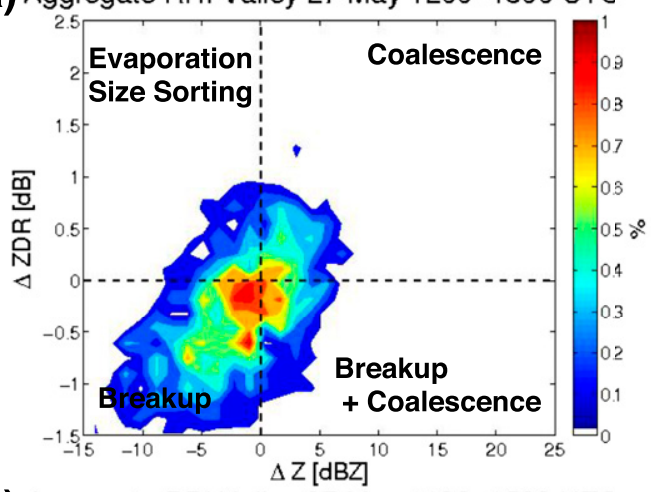

C) Aggregate PPI Valley 27 May $1100-1500$ UTC

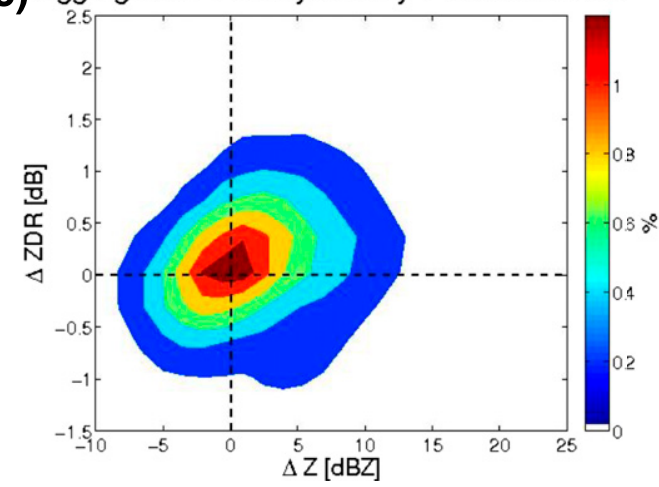

b) Aggregate RHI Ridge 27 May $1200-1300$ UTC

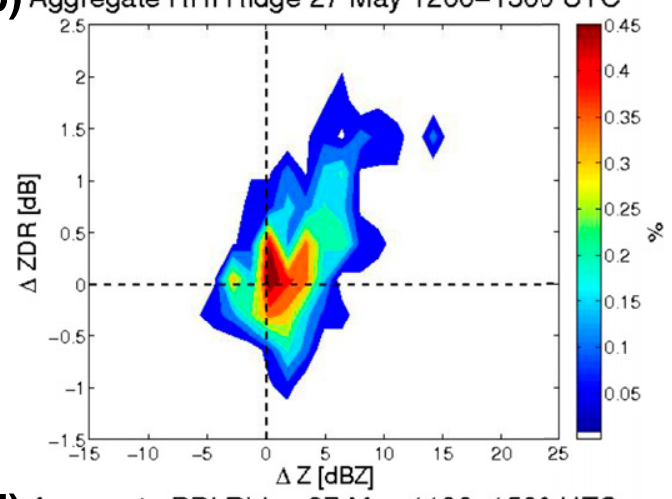

d) Aggregate PPI Ridge 27 May 1100-1500 UTC

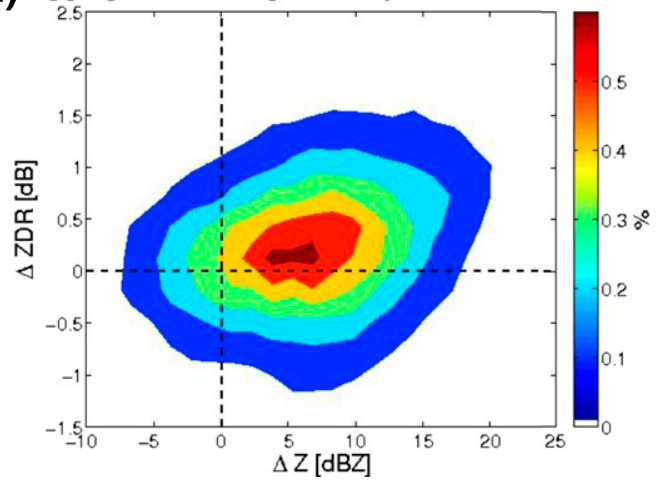

FIG. 10. Density plots of KR diagrams for RHIs over the (a) valley and (b) ridge and PPIs over the (c) valley and

(d) ridge. For reference, the qualitative descriptions of dominant microphysical regime are annotated in (a).

precipitation: size sorting/evaporation, breakup, coalescence, and a balance between breakup and coalescence. Size sorting/evaporation and coalescence result in an increase in differential reflectivity from the bright band to the surface, while breakup and the breakupcoalescence balance exhibit a decrease in differential reflectivity. In coalescence and breakup-coalescence regimes, reflectivity increases, while in size sorting/ evaporation and breakup processes, there is a negative change in reflectivity from the bright band to the surface. These regimes are annotated in the following figures for convenience.

The differences in $Z$ and $Z_{\mathrm{DR}}$ on 27 May 2014 in KR space, derived from the RHI scans within the 1200 UTC hour, are shown in Figs. 10a and 10b for locations along the ridge and valley. The KR parameter space from the PPI scans (39 full volume scans) from 1100 to 1500 UTC are shown in Figs. 10c and 10d. Over the valley, a variety of microphysical processes are ongoing, and the distribution of points is nearly centered over the origin of the KR plot. Over the ridge, the center of mass of the density plot shifts into the upper-right quadrant dominated by coalescence processes, as the melted aggregates fall and increase in size. Because the pattern of microphysical processes in the parameter space for both PPIs and RHIs is similar, PPIs perhaps may be used to discern microphysical regime from operational radar data.

\section{Summary and conclusions}

An IOP for the IPHEx experiment was conducted from 1 May to 15 June 2015 in the Great Smoky Mountains of North Carolina. During that time, the mobile dualpolarization radar, NOXP, was positioned within the Pigeon River basin for precipitation studies. Over the course of the IOP, the SCOP-ME precipitation algorithm based on NOXP radar observations performed comparably to, in terms of rainfall rate estimation, products derived from the operational radar network that benefited from a rain gauge-based bias adjustment and much better than the CMORPH satellite product when compared to independent research rain gauges in the region, particularly in terms of correlation with observed hourly precipitation totals. This result is attributed to the improved low-level coverage provided by the gap-filling radar and successful drop size distribution and rainfall retrievals by the SCOP-ME algorithm, as well as to the explicit use of dual-polarization information. Such high-frequency radars 
could be used to supplement the operational WSR-88D network without loss of performance in precipitation estimation in regions that suffer from more severe beam blockage than the Great Smoky Mountains, such as the western United States.

During the IOP, NOXP was also poised to observe the interactions of precipitation with the Great Smoky Mountains. On 27 May 2014, the radar was used to observe a case of widespread stratiform precipitation. Signatures of riming of ice particles and larger drops below the melting layer were observed over the ridgeline in the sector $20-30 \mathrm{~km}$ west of the radar, whereas these signatures are absent over the valley (5-15 $\mathrm{km}$ in range). CFADs of reflectivity and differential reflectivity suggest the presence of a greater concentration of supercooled water from 4 to $7 \mathrm{~km}$ MSL in this region, possibly due to sustained and enhanced updrafts of moist (or fog laden) air controlled by the topography. These patterns are present in other limited series of RHIs. Below the bright band and over the ridge, the change in $Z$ and $Z_{\mathrm{DR}}$ plotted in $\mathrm{KR}$ parameter space suggests a regime dominated by coalescence, while there is no dominant signal of one microphysical regime over another over the valley. This pattern is present both in PPIs and RHIs. In the absence of RHIs, as in an operational radar setting, this suggests that PPIs used in this framework may have utility in characterizing the dominant microphysical processes below the melting layer, presuming there is reasonable radar coverage at low levels. The enhanced coalescence over the ridgeline coincides with a climatological maximum in precipitation, and this mechanism provides a partial microphysical explanation for enhancing rainfall rates in these upslope regimes.

Although much of the success of the NOXP-derived precipitation products is attributed to better low-level radar coverage in the PRB, the location of the radar and its coverage in the vertical is insufficient for addressing precipitation-fog interactions. This study suggests, however, that in addition to precipitation-fog interactions and landform control of moisture convergence, the effects of topography on microphysical processes play a role in forming the observed precipitation gradients in complex terrain.

Acknowledgments. The authors thank the three anonymous reviewers for their helpful suggestions for improving this manuscript. The first author has been partially supported for this work by the NSF Graduate Research Fellowship under Grant DGE-1102691. Support for NOXP deployment was funded by the NASA ground validation campaign. Pierre Kirstetter acknowledges support through the NASA Precipitation Measurement Mission (PMM) Award NNX16AE39G and the NASA Ground Validation Program Award NNX16AL23G. The authors thank the radar operators at the National Severe Storms Laboratory and student assistants from the University of North Carolina at Asheville and Duke University for their help in collecting the data used in this study. Partial funding was provided by NOAA/Office of Oceanic and Atmospheric Research under NOAA-University of Oklahoma Cooperative Agreement NA11OAR4320072, U.S. Department of Commerce. Figures 6 and 7 have been generated using the Python ARM Radar Toolkit (PyART; Helmus and Collis 2016).

\section{REFERENCES}

Anagnostou, M. N., J. Kalogiros, F. S. Marzano, E. N. Anagnostou, M. Montopoli, and E. Piccioti, 2013: Performance evaluation of a new dual-polarization microphysical algorithm based on long-term X-band radar and disdrometer observations. J. Hydrometeor., 14, 560-576, https://doi.org/10.1175/ JHM-D-12-057.1.

,,- E. Nikolopoulos, Y. Derin, E. N. Anagnostou, and M. Borga, 2017: Satellite rainfall error analysis with the use of high-resolution X-band dual-polarization radar observations over the Italian Alps. Perspectives on Atmospheric Sciences, T. Karacostas, A. Bais, and P. Nastos, Eds., Springer, 279-286, https://doi.org/10.1007/978-3-319-35095-0_39.

Barros, A. P., and Coauthors, 2014: NASA GPM-ground validation: Integrated Precipitation and Hydrology Experiment 2014. NASA Tech. Rep., 64 pp., https://doi.org/10.7924/ G8CCOXMR.

Bringi, V. N., and V. Chandrasekar, 2001, Polarimetric Doppler Weather Radar: Principles and Applications. Cambridge University Press, 636 pp.

Chandrasekar, V., M. Schwaller, M. Vega, J. Carswell, K. Mishra, R. Meneghini, and C. Nguyen, 2010: Scientific and engineering overview of the NASA dual-frequency dual-polarized Doppler radar (D3R) system for GPM ground validation. Proc. 2010 IEEE Int. Geoscience and Remote Sensing Symp., Honolulu, HI, IEEE, 1308-1311, https://doi.org/10.1109/ IGARSS.2010.5649440.

Cifelli, R., V. Chandrasekar, S. Lim, P. C. Kennedy, Y. Wang, and S. A. Rutledge, 2011: A new dual-polarization radar rainfall algorithm: Application in Colorado precipitation events. J. Atmos. Oceanic Technol., 28, 352-364, https://doi.org/ 10.1175/2010JTECHA1488.1.

Daly, C., R. P. Neilson, and D. L. Phillips, 1994: A statisticaltopographic model for mapping climatological precipitation over mountainous terrain. J. Appl. Meteor., 33, 140-158, https://doi.org/ 10.1175/1520-0450(1994)033<0140:ASTMFM>2.0.CO;2.

, M. Halbleib, J. I. Smith, W. P. Gibson, M. K. Doggett, G. H. Taylor, J. Curtis, and P. P. Pasteris, 2008: Physiographically sensitive mapping of climatological temperature and precipitation across the conterminous United States. Int. J. Climatol., 28, 2031-2064, https://doi.org/10.1002/joc.1688.

Duan, Y., A. M. Wilson, and A. P. Barros, 2015: Scoping a field experiment: Error diagnostics of TRMM precipitation radar estimates in complex terrain as a basis for IPHEx2014. Hydrol. Earth Syst. Sci., 19, 1501-1520, https://doi.org/10.5194/ hess-19-1501-2015. 
Gori, E. G., and J. Joss, 1980: Changes of shape of raindrop size distributions simultaneously observed along a mountain slope. J. Rech. Atmos., 14, 239-300.

Gourley, J. J., D. P. Jorgensen, S. Y. Matrosov, and Z. L. Flamig, 2009: Evaluation of incremental improvements to quantitative precipitation estimates in complex terrain. J. Hydrometeor., 10, 1507-1520, https://doi.org/10.1175/2009JHM1125.1.

Grams, H. M., J. Zhang, and K. L. Elmore, 2014: Automated identification of enhanced rainfall rates using the near-storm environment for radar precipitation estimates. J. Hydrometeor., 15, 1238-1254, https://doi.org/10.1175/JHM-D-13-042.1.

Helmus, J. J., and S. M. Collis, 2016: The Python ARM Radar Toolkit (Py-ART), a library for working with weather radar data in the Python programming language. J. Open Res. Software, 4, e25, http://doi.org/10.5334/jors.119.

Hou, A. Y., and Coauthors, 2014: The Global Precipitation Measurement mission. Bull. Amer. Meteor. Soc., 95, 701-722, https://doi.org/10.1175/BAMS-D-13-00164.1.

Illingworth, A. J., and T. M. Blackman, 2002: The need to represent raindrop size spectra as normalized gamma distributions for the interpretation of polarization radar observations. J. Appl. Meteor., 41, 286-297, https://doi.org/10.1175/ 1520-0450(2002)041<0286:TNTRRS $>2.0 . C O ; 2$.

Jorgensen, D. P., M. N. Hanshaw, K. M. Schmidt, J. L. Laber, D. M. Staley, J. W. Kean, and P. J. Restrepo, 2011: Value of a dual-polarized gap-filling radar in support of Southern California post-fire debris-flow warnings. J. Hydrometeor., 12, 1581-1595, https://doi.org/10.1175/JHM-D-11-05.1.

Joyce, R. J., J. E. Janowiak, P. A. Arkin, and P. Xie, 2004: CMORPH: A method that produces global precipitation estimates from passive microwave and infrared data at high spatial and temporal resolution. J. Hydrometeor., 5, 487-503, https://doi.org/10.1175/ 1525-7541(2004)005<0487:CAMTPG >2.0.CO;2.

Kalogiros, J., M. N. Anagnostou, E. N. Anagnostou, M. Montopoli, E. Picciotti, and F. S. Marzano, 2013: Correction of polarimetric radar reflectivity measurements and rainfall estimates for apparent vertical profile in stratiform rain. J. Appl. Meteor. Climatol., 52, 1170-1186, https://doi.org/10.1175/JAMC-D-12-0140.1.

,,,,---- , and,- 2014 : Evaluation of a new polarimetric algorithm for rain-path attenuation correction of $\mathrm{X}$-band radar observations against disdrometer data. IEEE Trans. Geosci. Remote Sens., 52, 1369-1380, https://doi.org/ 10.1109/TGRS.2013.2250979.

Klazura, G. E., and D. A. Imy, 1993: A description of the initial set of analysis products available from the NEXRAD WSR-88D system. Bull. Amer. Meteor. Soc., 74, 1293-1311, https://doi.org/ 10.1175/1520-0477(1993)074<1293:ADOTIS > 2.0.CO;2.

Krajewski, W. F., A. Ntelekos, and R. Goska, 2006: A GIS-based methodology for the assessment of weather radar beam blockage in mountainous regions: Two examples from the US NEXRAD network. Comput. Geosci., 32, 283-302, https://doi.org/10.1016/ j.cageo.2005.06.024.

Kumjian, M. R., and A. V. Ryzhkov, 2012: The impact of size sorting on the polarimetric radar variables. J. Atmos. Sci., 69, 2042-2060, https://doi.org/10.1175/JAS-D-11-0125.1.

—, and O. P. Prat, 2014: The impact of raindrop collisional processes on the polarimetric radar variables. J. Atmos. Sci., 71, 3052-3067, https://doi.org/10.1175/JAS-D-13-0357.1.

— , S. Mishra, S. E. Giangrande, T. Toto, A. V. Ryzhkov, and A. Bansemer, 2016: Polarimetric radar and aircraft observations of saggy bright bands during MC3E. J. Geophys. Res. Atmos., 121, 3584-3607, https://doi.org/10.1002/ 2015JD024446.
Lin, Y., and K. E. Mitchell, 2005: The NCEP stage II/IV hourly precipitation analyses: Development and applications. 19th Conf. on Hydrology, San Diego, CA, Amer. Meteor. Soc., 1.2, http://ams.confex.com/ams/pdfpapers/83847.pdf.

Löffler-Mang, M., and J. Joss, 2000: An optical disdrometer for measuring size and velocity of hydrometeors. J. Atmos. Oceanic Technol., 17, 130-139, https://doi.org/10.1175/ 1520-0426(2000)017<0130:AODFMS > 2.0.CO;2.

Maddox, R. A., J. Zhang, J. J. Gourley, and K. W. Howard, 2002: Weather radar coverage over the contiguous United States. Wea. Forecasting, 17, 927-934, https://doi.org/10.1175/15200434(2002)017<0927:WRCOTC > 2.0.CO;2.

Matrosov, S. Y., D. E. Kingsmill, B. E. Martner, and F. M. Ralph, 2005: The utility of X-band polarimetric radar for quantitative estimates of rainfall parameters. J. Hydrometeor., 6, 248-262, https://doi.org/10.1175/JHM424.1.

Picciotti, E., and Coauthors, 2013: Coupling X-band dual-polarized mini-radars and hydro-meteorological forecast models: The HYDRORAD project. Nat. Hazards Earth Syst. Sci., 13, 1229-1241, https://doi.org/10.5194/nhess-13-1229-2013.

Porcù, F., L. P. D'Adderio, F. Prodi, and C. Caracciolo, 2013: Effects of altitude on maximum raindrop size and fall velocity as limited by collisional breakup. J. Atmos. Sci., 70, 1129-1134, https://doi.org/10.1175/JAS-D-12-0100.1.

Prat, O. P., and A. P. Barros, 2010: Ground observations to characterize the spatial gradients and vertical structure of orographic precipitation-Experiments in the inner region of the Great Smoky Mountains. J. Hydrol., 391, 141-156, https://doi. org/10.1016/j.jhydrol.2010.07.013.

Ryzhkov, A. V., S. E. Giangrande, and T. J. Schuur, 2005a: Rainfall estimation with a polarimetric prototype of WSR88D. J. Appl. Meteor., 44, 502-515, https://doi.org/10.1175/ JAM2213.1.

— T. J. Schuur, D. W. Burgess, P. L. Heinselman, and S. E. Giangrande, 2005b: The Joint Polarization Experiment: Polarimetric rainfall measurements and hydrometeor classification. Bull. Amer. Meteor. Soc., 86, 809-824, https://doi.org/ 10.1175/BAMS-86-6-809.

Squires, P., 1956: The micro-structure of cumuli in maritime and continental air. Tellus, 8, 443-444, https://doi.org/10.3402/ tellusa.v8i4.9040

Tao, J., and A. P. Barros, 2013: Prospects for flash flood forecasting in mountainous regions-An investigation of Tropical Storm Fay in the southern Appalachians. J. Hydrol., 506, 69-89, https://doi.org/10.1016/j.jhydrol.2013.02.052.

Testud, J., E. Le Bouar, E. Obligis, and M. Ali-Mehenni, 2000: The rain profiling algorithm applied to polarimetric weather radar. J. Atmos. Oceanic Technol., 17, 332-356, https://doi.org/ 10.1175/1520-0426(2000)017<0332:TRPAAT >2.0.CO;2.

Ulbrich, C. W., and D. Atlas, 2008: Radar measurement of rainfall with and without polarimetry. J. Appl. Meteor. Climatol., 47, 1929-1939, https://doi.org/10.1175/2007JAMC1804.1.

Vitale, J. D., and T. Ryan, 2013: Operational recognition of high precipitation efficiency and low-echo-centroid convection. J. Oper. Meteor, 1, 128-143, https://doi.org/10.15191/ nwajom.2013.0112.

Westrick, K. J., C. F. Mass, and B. A. Colle, 1999: The limitations of the WSR-88D radar network for quantitative precipitation measurement over the coastal western United States. Bull. Amer. Meteor. Soc., 80, 2289-2298, https://doi.org/10.1175/ 1520-0477(1999)080<2289:TLOTWR >2.0.CO;2.

Wilson, A. M., and A. P. Barros, 2014: An investigation of warm rainfall microphysics in the southern Appalachians: Oro- 
graphic enhancement via low-level seeder-feeder interactions. J. Atmos. Sci., 71, 1783-1805, https://doi.org/10.1175/ JAS-D-13-0228.1.

— , and — 2015: Landform controls on low level moisture convergence and the diurnal cycle of warm season orographic rainfall in the southern Appalachians. J. Hydrol., 531, 475-493, https://doi.org/10.1016/j.jhydrol.2015.10.068.

Xu, X., K. Howard, and J. Zhang, 2008: An automated radar technique for the identification of tropical precipitation. J. Hydrometeor, $\mathbf{9}$, 885-902, https://doi.org/10.1175/2007JHM954.1.

Young, C. B., B. R. Nelson, A. A. Bradley, J. A. Smith, C. D. PetersLidard, A. Kruger, and M. L. Baeck, 1999: An evaluation of NEXRAD precipitation estimates in complex terrain. J. Geophys. Res., 104, 19691-19703, https://doi.org/10.1029/1999JD900123.

Yuter, S. E., and R. A. Houze Jr., 1995: Three-dimensional kinematic and microphysical evolution of Florida cumulonimbus. Part II:
Frequency distributions of vertical velocity, reflectivity, and differential reflectivity. Mon. Wea. Rev., 123, 1941-1963, https://doi. org/10.1175/1520-0493(1995)123<1941:TDKAME>2.0.CO;2.

Zhang, J., and Coauthors, 2016: Multi-Radar Multi-Sensor (MRMS) quantitative precipitation estimation: Initial operating capabilities. Bull. Amer. Meteor. Soc., 97, 621-638, https:/doi.org/10.1175/ BAMS-D-14-00174.1.

Zrnić, D. S., and A. V. Ryzhkov, 1999: Polarimetry for weather surveillance radars. Bull. Amer. Meteor. Soc., 80, 389-406, https://doi.org/10.1175/1520-0477(1999)080<0389: PFWSR $>2.0 . \mathrm{CO} ; 2$.

Zwiebel, J., J. Van Baelen, S. Anquetin, Y. Pointin, and B. Boudevillain, 2016: Impacts of orography and rain intensity on rainfall structure. The case of the HyMeX IOP7a event. Quart. J. Roy. Meteor. Soc., 142, 310-319, https://doi.org/ 10.1002/qj.2679. 